\title{
Globe
}

Revue internationale d'études québécoises

Jean-Guy Sabourin : Une fenêtre sur la modernité. Les

Apprentis-Sorciers (1955-1968). Montréal, VLB éditeur, 2003

\section{Sophie Létourneau}

Volume 7, numéro 1, 2004

URI : https://id.erudit.org/iderudit/1000837ar

DOI : https://doi.org/10.7202/1000837ar

Aller au sommaire du numéro

Éditeur(s)

Globe, Revue internationale d'études québécoises

ISSN

1481-5869 (imprimé)

1923-8231 (numérique)

Découvrir la revue

Citer ce compte rendu

Létourneau, S. (2004). Compte rendu de [Jean-Guy Sabourin : Une fenêtre sur la modernité. Les Apprentis-Sorciers (1955-1968). Montréal, VLB éditeur, 2003].

Globe, 7(1), 210-211. https://doi.org/10.7202/1000837ar d'utilisation que vous pouvez consulter en ligne.

https://apropos.erudit.org/fr/usagers/politique-dutilisation/ 
qu'Ollivier Hubert lance à tous les chercheurs par cette œuvre couronnée, à juste titre, du prix Lionel-Groulx de l'Institut d'histoire de l'Amérique française. Cet ouvrage demeurera pour longtemps une lecture obligée pour tous les québécistes.

Louis Rousseau

Université du Québec à Montréal

\section{Jean-Guy Sabourin}

Une fenêtre sur la modernité.

Les Apprentis-Sorciers (1955-1968).

Montréal, VLB éditeur, 2003.

Jean-Guy Sabourin a été pendant plusieurs années le directeur de la troupe amateure des Apprentis-Sorciers, troupe qu'il a fondée avec Jean Bellemare et Michel Côté. Leur objectif : diffuser les " nouveaux courants théâtraux " (surtout le théâtre de Brecht et d'Ionesco) et de nouvelles façons de penser le lien de l'individu à la société. On s'aperçoit finalement que la raison d'être de la troupe était plutôt de partager, dans la bonne humeur et l'esprit de famille, une passion pour le théâtre contemporain. Des salles paroissiales jusqu'à la Boulangerie, son principal lieu de résidence, Sabourin décrit le parcours de la troupe, la suite des saisons et les événements marquants, notamment la création d'Au nom de la rose de Pierre Perreault. On y croise également Gaston Miron, Félix Leclerc, Jean-Pierre Ferland et Jacques Ferron. Ce livre écrit comme un journal de bord a posteriori est ponctué des critiques qu'ont faites à l'époque Yerri Kempf, Gérald Godin, Jean Basile et Jean Hamelin. Des photos et des témoignages de quelques Apprentis-Sorciers (qui rendent compte de l'importance qu'ont eu dans leur vie les années passées avec la troupe) complètent le document. On aurait aimé que l'auteur d'un livre qui s'intitule Une fenêtre sur la modernité réfléchisse un peu plus sur sa pratique, qu'il explique son travail, sa recherche, plutôt que de simplement résumer les pièces jouées en énumérant des noms. On comprend donc qu'il ne s'agit pas d'un ouvrage critique, mais d'un livre de souvenirs dans lequel se lisent la fierté, la ferveur et le dynamisme de 
l'auteur et des autres membres de la troupe, et le bonheur partagé du théâtre amateur.

Sophie Létourneau

Université de Montréal

\section{Miléna Santoro}

\section{Mothers of Invention. Feminist Autbors and Experimental Fiction in France and Quebec. McGill-Queen's University Press, 2002.}

La littérature féministe, qui s'est développée en force au cours des années 1970, se veut le dernier avatar de l'avant-garde littéraire éclose quelques années auparavant. C'est à tout le moins ce que soutient Miléna Santoro en s'appuyant entre autres sur les travaux de Susan Suleiman (Subversive Intent. Gender, Politics, and the Avant-Garde, 1990). Inspirée des thèses développées dans Subversive Intent, où l'auteure montre que la critique féministe a remis en question l'idéologie patriarcale qui, bien entendu, n'a pas épargné l'avant-garde, Santoro se propose d'étudier, dans l'ouvrage Mothers of Invention, les textes de quatre écrivaines, décrites comme "les mères de l'invention ". Plus précisément, il s'agit d'identifier une suite de romans qui ont en commun une esthétique subversive participant de la tradition de l'avant-garde et la transformant tout à la fois : "[Motbers of Invention] focuses on fiction in an attempt to show the enduring power of the creative impulses born of these women's personal experiences and feminist trajectories * (p. 6). Santoro envisage de montrer comment la relecture des images de la féminité et de la maternité, relecture conjuguée à une approche disruptive du langage et des genres littéraires, caractérise un projet d'écriture favorisant l'expression de la subjectivité des femmes. C'est au moyen des textes romanesques de Hélène Cixous ( $L a$ ), de Madeleine Gagnon (Lueur), de Nicole Brossard (L'amèr ou le chapitre effritê) et de Jeanne Hyvrard (Les prunes de Cythère, Mère la mort et La meurtritude) que la critique entend étayer son propos.

Le roman $L a$ retient d'entrée de jeu l'attention de Santoro. Hélène Cixous signe en 1976 ce texte qui illustre une quête de différence et de 